\title{
TABUS ALIMENTARES EM REGIÃO DO NORTE DO BRASIL"
}

\author{
Marlene Trigo "* \\ Maria José Roncada** \\ Glacilda Telles de Menezes Stewien" \\ Isabel Maria Teixeira Bicudo Pereira**
}

TRIGO, M. et al. Tabus alimentares em regiăo do Norte do Brasil. Rev.Saúde públ, S.Paulo, 23: 455-64, 1989.

\begin{abstract}
RESUMO: Foi realizado um inquérito sobre tabus alimentares em duas localidades do Municipio de Marabá, PA, Brasil: São Félix e Murumuru, tendo sido estudadas, respectivamente, 90 e 35 famllias. Dos tabus alimentares encontrados, foi grande a restriçāo feita à ịngestão simultânea de leite com várias frutas, especialmente com manga, laranja, cajú e abacaxi; também a ingestảo simultânea de ovos com frutas foram referidas como hábitos que devem ser evitados, assim como a mistura de carne de mamíferos com peixes. Quanto a ingestão simultânea de frutas, destaca-se a proibição de uma fruta regional, o açal, com outras 10 frutas. Foi mais elevado o número de restriçóes alimentares durante a lactação do que durante a gravidez, principalmente de carne de caça e de peixes, abundantes na regiāo estudada. Os motivos mais citados para justificar os tabus alimentares foram: "faz mal", "mata", "congestăo" e "vômito".
\end{abstract}

DESCRITORES: Tabu alimentar. Inqueritos sobre dietas.

\section{1 - INTRODUÇÃO}

O estado nutricional de uma comunidade depende, principalmente, da existência e possibilidade de acesso a alimentos indispensáveis à sobrevivência. Entretanto, existem outros fatores que vão limitar ou ampliar o consumo dos alimentos disponiveis. Entre esses, destaca-se um de importância ímpar: o componente comportamental que caracteriza cada indivíduo.

É na ação das pessoas, no momento em que escolhem um alimento, em detrimento de outros, que se pode identificar o grau de comprometimento que têm com padrōes culturais (costumes regionais, tradições familiares, crenças, hábitos e tabus), capazes até de impedir que alimentos existentes em abundância sejam consumidos.

Segundo Jelliffe 6 "cada uma das múltiplas comunidades humanas tem sua própria estrutura de comportamento, costumes e crenças, o conjunto das quais define sua propria "cultura". Em todas as culturas há práticas e costumes que são proveitosas para a saúde e nutrição do grupo, e algumas que são nocivas. Nenhuma cultura tem o monopólio da sabedoria nem do absurdo".

Tal ponto de vista é partilhado por Witt ${ }^{19}$, quando afirma que conhecimentos sobre nutrição e hábitos alimentares têm potencial para determinar o que deve ser consumido, contribuindo, assim, para o aparecimento ou agravamento de problemas nutricionais.

No Brasil, país de amplitude continental, o panorama alimentar é complexo e peculiar a cada regiāo. Assim, na Região Norte, a formação de hábitos e tabus alimentares foi determinada por forte influência indígena, pela presença do branco e do negro e pelas características geográficas que lhe são proprias. Esses fatores, associados à religiosidade popular, leva à sensível heterogeneidade de hábitos alimentares locais, tendo, cada microrregião, sua dieta básica característica ${ }^{3}$.

Tal situação mostra que qualquer intervenção na área ligada à alimentação e nutrição, prin-

- Apresentado no $1^{\circ}$ Congresso Nacional da Sociedade Brasileira de Alimentação e Nutrição. Săo Paulo, 1987.

** Departamento de Nutrição da Faculdade de Saúde Pública da Universidade de São Paulo - Av. Dr. Arnaldo, 715 - 01255 São Paulo, SP - Brasil.

- Departamento de Prática de Saúde Pública da Faculdade de Saúde Pública da Universidade de São Paulo-Av. Dr. Arnaldo, 715 - 01255 - São Paulo, SP - Brasil. 
cipalmente quando envolve aspectos educativos, requer, como pré-requisito, um conhecimento detalhado não só da regiåo, mas da localidade propriamente dita.

Elaborou-se o presente estudo com o objetivo de identificar opiniōes sobre tabus alimentares emitidas por mães residentes no Município de Marabá, Estado do Pará, cujos resultados possam subsidiar programas de educação nutricional que venham a se desenvolver na Regiāo Norte do País. Especificamente estudar-se-ăo tabus alimentares ligados a estados fisiológicos, como gestaçăo e lactação, além de proibições de ingestão de misturas de alimentos.

\section{2-METODOLOGIA}

O estudo foi realizado em Murumuru e São Félix, localidades pertencentes ao Município paraense de Marabá, situado na confluência dos rios Tocantins e Itacaúnas, na Região Norte do Brasil. (Figura)

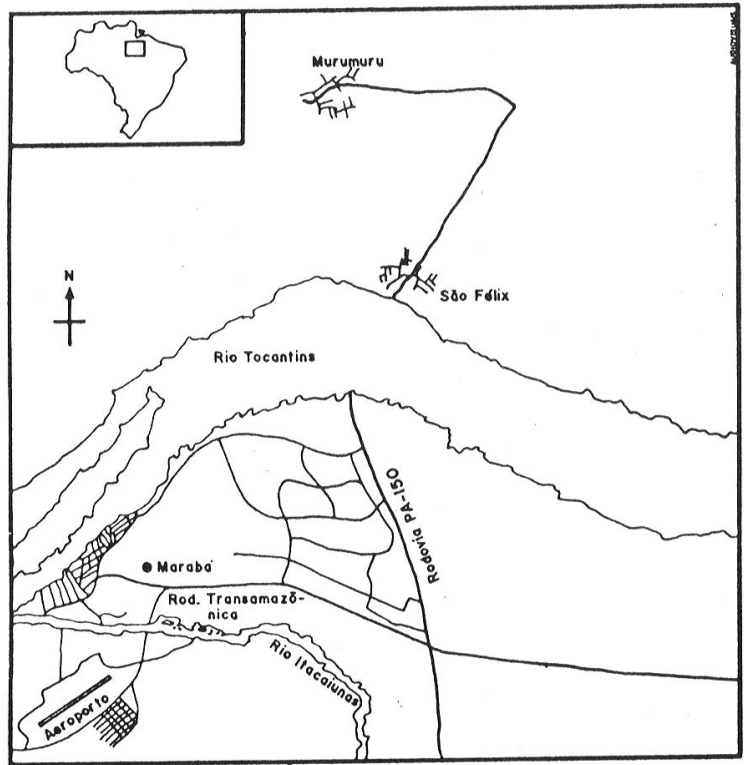

Figura-Localização geográfica das duas localidades estudadas, São Félix e Murumuru. Marabá, Pará, 1980.

Embora consideradas zonas rurais, as duas localidades apresentavam características distintas: Murumuru dedicava-se quase que exclusivamente à agricultura, enquanto São Félix tinha atividades mais diversificadas, como construçăo civil e pequeno comercio varejista, além de uma pequena indústria de barcos. $\mathrm{Na}$ época (ano de 1980), ambas eram atendidas pelo Setor Saúde do Projeto Rondon, atraves do Campus Avançado de Marabá, pertencente à Universidade de São Paulo, com atuação de alunos de graduação das áreas biológicas.

Um cadastramento prévio determinou o número de domićlios e de famílias residentes nas duas localidades: 154 domicílios, com 479 individuos em Murumuru, e 644 domićlios com 2.275 pessoas em São Félix. Realizou-se então amostragem probabilística, sorteando-se 35 domićlios (com 194 pessoas) em Murumuru e 90 (com 528 pessoas) em São Félix. Estabeleceu-se como critério que as informações, em cada domićlio sorteado, seriam fornecidas apenas pelas mães com filhos menores de 5 anos.

Utilizou-se como instrumento para coleta de dados formulário com questōes abertas e fechadas, com a finalidade de se conhecer o grau de instruçăo das mães, sua procedência (por Estados), a renda familiar média "per capita" em salários mínimos (SMPC) e informações referentes a tabus alimentares.

$O$ instrumento foi pré-testado no mesmo local, com população semelhante, dois meses antes da sua aplicação.

\section{3 - RESULTADOS E DISCUSSÃO}

A Tabela 1 apresenta alguns atributos referentes às mães estudadas, visando melhor caracterizá-las. Em relação à renda familiar, podemos observar que 77,1\% em Murumuru e 77,7\% em São Félix tinham renda média "per capita" até um salário mínimo. Mais da metade dessas famílias não alcançava 0,5 salário mínimo por pessoa: $62,8 \%$ em Murumuru e 54,4\% em São Félix.

Quanto ao grau de instrução (Tabela 1), nota-se que predominou o número de analfabetas e de máes com curso primário incompleto. Apenas cerca de 5\% em Murumuru e de $15 \%$ em São Félix tinham curso primário ou ginasial completos. Este aspecto deve ser levado em consideração ao se pretender planejar orientação nutricional nessas comunidades.

Quanto à procedência dessas mães (Tabela 1), observa-se que cerca de um terço em São Félix e menos de $10 \%$ em Murumuru são autoctones;

\footnotetext{
- Salário mínimo per capita: maio de 1980, Cr\$ 3.463,80, equivalente a US\$ 65.69.
} 
TABELA 1

Caracterização das măes estudadas, segundo renda familiar, graus de instruç̧o e procedencia, em duas localidades do Municlpio de Maraba, PA. 1980.

Atributos

$\begin{array}{ll}\text { Såo Félix } & \text { Murumuru } \\ \text { N}^{0} & \text { No }\end{array}$

Renda Familiar (SMPC)*

$<0,5$

$0,5-1,0$

$>1,0$

Recebem em espécie

Graus de instruçăo materna

Sem instruçăo

Primário incompleto

Primário completo

Ginásio incompleto

Procedéncia Materna

(Unidades da Federação)

\section{Pará}

Goiás

Maranhăo

Bahia

Outras

$\begin{array}{rrrr}49 & 54,4 & 22 & 62,8 \\ 21 & 23,3 & 5 & 14,3 \\ 9 & 10,0 & 1 & 2,9 \\ 11 & 12,2 & 7 & 20,0\end{array}$

- SMPC = salário mínimo per capita: maio de 1980, Crs $3.436,80$, equivalente a US\$ 65.69

* Mãe com ginásio completo

** Outras Unidades da Federação: Amapá, Piauí, Ceará, Parafba, Pernambuco, Espirito Santo e Minas Gerais

a maioria veio de estados vizinhos, como o Maranhão, ou então procederam da Bahia, como aparece em Murumuru. A maioria dessas mães residiam há mais de 5 anos na região, ou seja, cerca de $68 \%$ em São Félix e $51 \%$ em Murumuru.

\section{1 - Conceitos relacionados a proibições de ingestáo de mistura de alimentos}

\subsection{1 - Opiniāo das mães sobre mistura de leite com outros alimentos}

Optou-se por elaborar as tabelas apenas com dados referentes àquelas mães que relataram informaçōes que se afiguravam como tabus alimentares.

Na Tabela 2 estão relacionados os alimentos que algumas mães referiram não deverem ser misturados ao leite. Observa-se nas duas localidades que as frutas foram os alimentos citados
TABELA 2

Alimentos que năo devem ser misturados ao leite, segundo opiniáo de 30 máes de Såo Félix e 23 mâes de Murumuru, Município de Marabá, PA 1980.

\begin{tabular}{|c|c|c|c|}
\hline \multicolumn{2}{|c|}{ São Felix } & \multicolumn{2}{|c|}{ Murumuru } \\
\hline Alimentos & Freqũência & Alimentos & Freqüencia" \\
\hline $\begin{array}{l}\text { Manga } \\
\text { Laranja } \\
\text { Melancia } \\
\text { Bacuri } \\
\text { Caju } \\
\text { Açai } \\
\text { Abacaxi } \\
\text { Mamão } \\
\text { Banana } \\
\text { Ananás } \\
\text { Limão } \\
\text { Abacate } \\
\text { Jaca } \\
\text { Buriti } \\
\text { Maçã } \\
\text { Qualquer Fruta }\end{array}$ & $\begin{array}{l}12 \\
7 \\
6 \\
6 \\
5 \\
4 \\
3 \\
3 \\
3 \\
2 \\
2 \\
1 \\
1 \\
1 \\
1 \\
1\end{array}$ & $\begin{array}{l}\text { Manga } \\
\text { Abacaxi } \\
\text { Laranja } \\
\text { Caju } \\
\text { Limåo } \\
\text { Bacuri } \\
\text { Abóbora } \\
\text { Açai } \\
\text { Mamåo } \\
\text { Fava } \\
\text { Fruta Ácida } \\
\text { Cupuaçu } \\
\text { Melancia } \\
\text { Batata }\end{array}$ & $\begin{array}{c}11 \\
11 \\
7 \\
3 \\
3 \\
3 \\
2 \\
2 \\
1 \\
1 \\
1 \\
1 \\
1 \\
1\end{array}$ \\
\hline
\end{tabular}

- Resposta Múltipla

praticamente por todas, destacando-se, principalmente, fontes de carotenóides e de vitamina $C$, como manga, laranja, abacaxi e cajú.

Segundo Castro a proibiçáo de leite com manga é a intekdição mais generalizada entre nós, que vai desde o Norte ate o Sul do País; a laranja e a fruta freqüentemente restringida, principalmente em relação a determinados períodos do dia: "De manhã laranja é ouro, de tarde é prata e de noite mata"2.

O mesmo autor, ao se referir aos tabus alimentares no Brasil, o fez com reservas. Para ele, nossos tabus não tinham o verdadeiro significado de coisa sagrada e misteriosa, ao contrário do que ocorria em países da África Oriental, Austrália e Polinesia, onde alimentar-se era um ato repleto de rituais e sempre controlado por inúmeros tabus ${ }^{2}$.

Enquanto em Murumuru 23 mães $(66,0 \%)$ mostra ram alguma restrição em relação à mistura de leite com certos alimentos, em São Félix apenas $30(33,0 \%)$ o fizeram; nesta localidade, 3 mães informaram não consumir leite.

A proibição de misturar leite com determi- 
TABELA 3

Frutas que não podem ser consumidas simultaneamente, segundo, a opinião de 45 mães de São Félix e 11 mães de Murumuru, Município de Marabá, PA. 1980.

\begin{tabular}{|c|c|c|c|c|c|}
\hline \multicolumn{3}{|c|}{ São Félix } & \multicolumn{3}{|c|}{ Murumuru } \\
\hline Frutas & & Freqüência* & Frutas & & Freqüência* \\
\hline Abacate & $\begin{array}{l}\text { - Ananás } \\
\text { - Lima } \\
\text { - Melancia }\end{array}$ & $\begin{array}{l}1 \\
1 \\
1\end{array}$ & Açaí & $\begin{array}{l}\text { - Cupuaçu } \\
\text { - Fruta ácida } \\
\text { - Laranja } \\
\text { - Limão }\end{array}$ & $\begin{array}{l}1 \\
1 \\
1 \\
1\end{array}$ \\
\hline \multirow[t]{3}{*}{ Açaí } & $\begin{array}{l}\text { - Melancia } \\
\text { - Limâo } \\
\text { - Fruta ácida }\end{array}$ & $\begin{array}{l}4 \\
3 \\
2\end{array}$ & & - Outra fruta & $\begin{array}{l}1 \\
1\end{array}$ \\
\hline & $\begin{array}{l}\text { - Laranja } \\
\text { - Outra fruta } \\
\text { - Manga }\end{array}$ & $\begin{array}{l}2 \\
2 \\
1\end{array}$ & Bacuri & $\begin{array}{l}\text { - Açaí } \\
\text { - Manga }\end{array}$ & $\begin{array}{l}1 \\
1\end{array}$ \\
\hline & & & Banana & - Caju & 1 \\
\hline \multirow[t]{2}{*}{ Ananás } & $\begin{array}{l}\text { - Manga } \\
\text { - Laranja }\end{array}$ & $\begin{array}{l}3 \\
2\end{array}$ & & -Caqui & 1 \\
\hline & - Outra fruta & 1 & Caju & $\begin{array}{l}\text { - Limão } \\
\text { - Manga }\end{array}$ & $\begin{array}{l}1 \\
2\end{array}$ \\
\hline \multirow[t]{3}{*}{ Bacuri } & $\begin{array}{l}\text { - Outra fruta } \\
\text { - Açaí }\end{array}$ & $\begin{array}{l}9 \\
1\end{array}$ & & - Laranja & 1 \\
\hline & $\begin{array}{l}\text { - Ananás } \\
\text { - Mamáo }\end{array}$ & $\begin{array}{l}1 \\
1\end{array}$ & Mamão & - Caju & 1 \\
\hline & & & Outras & - Laranja c/ limão & 1 \\
\hline Banana & $\begin{array}{l}\text { - Caju } \\
\text { - Laranja } \\
\text { - Outra fruta }\end{array}$ & $\begin{array}{l}1 \\
1 \\
1\end{array}$ & & $\begin{array}{l}\text { - Manga c/ cupuaçu } \\
\text { - Melancia c/ cupuaçu }\end{array}$ & $\begin{array}{l}1 \\
1\end{array}$ \\
\hline Caju & $\begin{array}{l}\text { - Abacaxi } \\
\text { - Açaí } \\
\text { - Manga } \\
\text { - Abacate } \\
\text { - Laranja }\end{array}$ & $\begin{array}{l}3 \\
3 \\
2 \\
1 \\
1\end{array}$ & & & \\
\hline Mamão & $\begin{array}{l}\text { - Jaca } \\
\text { - Manga } \\
\text { - Laranja } \\
\text { - Outra fruta }\end{array}$ & $\begin{array}{l}2 \\
1 \\
1 \\
1\end{array}$ & & & \\
\hline Outras & - Fruta - pão c/ outra & 1 & & & \\
\hline
\end{tabular}

* Resposta múl tipla.

nados alimentos também foi observada em alguns trabalhos realizados pela Comissão Nacional de Alimentação (CNA), nos Estados de Goiás ${ }^{17}$, Bahia ${ }^{5}$ e Rio Grande do Norte ${ }^{11}$. Nesses estudos destacaram-se, entre os alimentos proibidos, as frutas, em primeiro lugar; dentre estas, a manga aparece com evidência. Outras frutas citadas foram abacaxi, mamão, laranja e melancia.

\subsection{2 - Opiniäo das mães sobre mistura de frutas}

A Tabela 3, originada apenas da opinião das mães que apresentavam tabus em relação a frutas, mostra que o seu consumo simultâneo sofre influência desses tabus, tanto em São Félix, como em Murumuru. A primeira localidade mostrou um expressivo percentual de 50,0\% de mães apresentando tabus, enquanto na segunda, embora menor, atingiu $31,0 \%$. Isso se torna motivo de preocupação, quando se observa que as frutas mais recusadas (Tabela 3) são as ácidas, as cítricas e a manga, sugerindo que poderiam advir desse consumo insuficiente, deficiências nutricionais específicas, como as hipovitaminoses $\mathrm{C} \mathrm{e} \mathrm{A.}$

A literatura disponível mostra que assim como existe a crença de que determinados alimentos ajudam na cura de certas doenças, acredita-se tambem que outros alimentos, ou sua mistura, podem causar doenças, e um exemplo concreto disso está no depoimento dessas mães.

Com relação à rejeiçăo ao consumo simul- 
TABELA 4

Alimentos que não podem ser consumidas simultaneamente, segundo, a opinião de 28 mães de São Félix e 11 mães de Murumuru. Município de Marabá, PA. 1980.

\begin{tabular}{|c|c|c|c|c|c|}
\hline \multicolumn{3}{|c|}{ São Félix } & \multicolumn{3}{|c|}{ Murumuru } \\
\hline Alimento & & Frequiência* & Alimen & & Frequüência* \\
\hline Caça & $\begin{array}{l}\text { - Couve manteiga } \\
\text { - Carne de vaca }\end{array}$ & $\begin{array}{l}1 \\
1\end{array}$ & Porco & - Carne de peixe & 1 \\
\hline Galinha & $\begin{array}{l}\text { - Tatu } \\
\text { - Carne de vaca }\end{array}$ & $\begin{array}{l}1 \\
1\end{array}$ & Ovo & $\begin{array}{l}\text { - Abacaxi } \\
\text { - Manga } \\
\text { - Mamão } \\
\text { - Abacate c/ leite }\end{array}$ & $\begin{array}{l}4 \\
3 \\
2 \\
1\end{array}$ \\
\hline Peixe & $\begin{array}{l}\text { - Carne de vaca } \\
\text { - Carne de caça }\end{array}$ & $\begin{array}{l}5 \\
4\end{array}$ & & $\begin{array}{l}\text { - Açaí } \\
\text { - Banana prata } \\
\text { - Cachaça }\end{array}$ & $\begin{array}{l}1 \\
1 \\
1\end{array}$ \\
\hline Porco & $\begin{array}{l}\text { - Carne de peixe } \\
\text { - Carne de caça }\end{array}$ & $\begin{array}{l}1 \\
1\end{array}$ & & $\begin{array}{l}\text { - Caju } \\
\text { - Laranja } \\
\text { - Melancia }\end{array}$ & $\begin{array}{l}1 \\
1 \\
1\end{array}$ \\
\hline Ovo & $\begin{array}{l}\text { - Bacuri } \\
\text { - Manga } \\
\text { - Melancia } \\
\text { - Mamão } \\
\text { - Caju } \\
\text { - Açaí } \\
\text { - Carambola } \\
\text { - Laranja } \\
\text { - Peixe } \\
\text { - Pepino } \\
\text { - Piqui }\end{array}$ & $\begin{array}{l}5 \\
4 \\
4 \\
3 \\
2 \\
1 \\
1 \\
1 \\
1 \\
1 \\
1\end{array}$ & Outros & $\begin{array}{l}\text { - Banha c/ abacaxi } \\
\text { - Café c/ alim. frio } \\
\text { - Café c/ laranja } \\
\text { - Fígado c/ queijo }\end{array}$ & $\begin{array}{l}1 \\
1 \\
1 \\
1\end{array}$ \\
\hline Outros & $\begin{array}{l}\text { - Açaí c/ água } \\
\text { - Cupuaçu c/ outro } \\
\text { - Sardinha c/ carne }\end{array}$ & $\begin{array}{l}1 \\
1 \\
1\end{array}$ & & & \\
\hline
\end{tabular}

* Resposta múltipla.

tâneo de frutas, Cascudo ${ }^{1}$ afirma que sua origem remonta ao tempo de Hipócrates. Assim, segundo ele, as frutas eram consideradas de natureza "úmida e fria", podendo facilmente se alterar se ingeridas quentes, perturbando a digestão e gerando doenças.

\subsection{3 - Opinião das mães sobre mistura de alimentos}

A ingestão de alguns alimentos, simultaneamente, também constituiu tabus em São Félix $(30,0 \%)$ e Murumuru $(31,1 \%)$, como pode-se observar na Tabela 4.

Na primeira localidade esse tabu parece ser menos freqüente do que o relativo ao consumo simultâneo de frutas $(50,0 \%)$, enquanto na segunda a freqüência permanece a mesma $(31,1 \%)$. Poucas combinações de alimentos são consideradas tabus simultaneamente nas duas cidades: carne com peixe e ovo com frutas. Proibições semelhantes foram apontadas em alguns trabalhos, onde misturar carne com peixe significa um dos tabus mais fortes de certos povos; como exemplo, o caso dos esquimós, citado por Castro ${ }^{2}$ onde não só o consumo de carne e peixe na mesma refeição é proibido, como também executar a caça e a pesca na mesma semana.

O mesmo resultado foi registrado pela CNA nos Estados de Goiás ${ }^{17}$, Bahia ${ }^{3}$ e Rio Grande do Norte ${ }^{11}$, onde ovo com frutas e carne com peixe são tabus apontados com freqüências elevadas.

\section{2 - Conceitos referentes a proibiçōes de ali- mentos durante a gestação}

A alimentação da gestante, assim como da nutriz, $\mathfrak{c}$ altamente influenciada pelos padrōes culturais que regem seu contexto social. Para essas mulheres existem os alimentos permitidos e os proibidos enquanto perduram seus estados fisiológicos. O estudo realizado mostra que a maioria das mulheres entrevistadas em São Félix e Murumuru não refere tabus alimentares ligados ao período de gravidez. Somente $5,5 \%$ das mulheres em São Félix e 17,1\% das de Murumuru 
referiram proibições de certos alimentos no período de gestação; os mais citados foram referentes aos grupos das frutas e das carnes. Há um aumento das necessidades nutricionais nesse período de vida. Restriçōes alimentares podem significar pouco ganho de peso na gestante, com conseqüente concepto de baixo peso ao nascer.

Estudos realizados pela CNA nos Estados do Rio Grande do Norte ${ }^{11}$, Espírito Santo ${ }^{10}$, Goiás ${ }^{17}$ e Bahia ${ }^{5}$ confirmam a presente pesquisa no que se refere a tabus alimentares durante a gestaçăo, quando também se constatou que poucas mulheres referiram alguma restrição de alimentos nesse período. Dentre os alimentos evita-

\section{TABELA 5}

Alimentos que nảo devem ser consumidos pela mulher que amamenta, segundo a opinião de 71 mães de São Félix, Munićpio de Marabá, PA. 1980.

\begin{tabular}{|c|c|c|}
\hline $\begin{array}{l}\text { Alimentos de } \\
\text { origem } \\
\text { animal }\end{array}$ & Freqüência & $\begin{array}{l}\text { Alimentos de Freqüência* } \\
\text { origem } \\
\text { vegetal }\end{array}$ \\
\hline
\end{tabular}

\begin{tabular}{lcll} 
Caça"* & 36 & Abacaxi & 4 \\
Peixe de Couro** & 22 & Laranja & 4 \\
Paca & 18 & Feijão & 4 \\
Surubim & 15 & Limão & 3 \\
Ovos & 12 & Banana & 3 \\
Veado & 9 & Frutas Ácidas & 3 \\
Peixe & 9 & Fava & 2 \\
Porco & 8 & Melancia & 2 \\
Caititu & 8 & Mamão & 2 \\
Jabuti & 7 & Castanha do Pará & 1 \\
Tatu & 6 & Cupuaçu & 1 \\
Anta & 5 & Abóbora & 1 \\
Pato & 3 & Inhame & 1 \\
Pacu-Manteiga & 3 & Abacate & 1 \\
Bucho & 2 & Banana Prata & 1 \\
Pintado & 2 & & \\
Galinha & 2 & & \\
Capote & 2 & & \\
Capivara & 1 & & \\
Cabeça de Bovino & 1 & & \\
Bode & 1 & & \\
Curimbata & 1 & & \\
Língua de Bovino & 1 & \\
Leitoa & 1 & \\
Leite & 1 & & \\
\hline
\end{tabular}

- Resposta Múltipla

- Caça do mato, sem especificar qual.

Peixe de couro, sem especificar qual. dos foram citados: abóbora, carne seca, figado de boi, jaca e abacaxi.

Em estudo realizado na Amazónia, entre 1954 e 1956, a CNA ${ }^{12}$ entrevistou 538 mulheres, das quais $10,6 \%$ informaram se abster de certos alimentos durante a gravidez, como carne de boi, peixe gordo, feijāo e leite.

Estudos realizados na India por Jyothi e col. $^{7}$ em 1963, Khanum e Umapathy ${ }^{8}$ (1976) e $\mathrm{Rao}^{13}$ (1985), com mulheres grávidas, mostraram que os alimentos evitados nesse período eram o mamão e gergelim, por serem abortivos; o leite e carne, por dificultarem o parto; e ovos, por causarem o aparecimento de manchas vermelhas no corpo e rosto das crianças.

\section{3 - Conceitos referentes a proibições de ali- mentos durante a lactaçño}

As Tabelas 5 e 6 apresentam, em ordem decrescente, a opinião de $79,0 \%$ das mães estudadas em São Félix e 68,0\% das de Murumuru, sobre os alimentos que não devem ser consumidos pela mulher que amamenta. A caça do mato foi o alimento mais citado entre os de origem

TABELA 6

\section{Alimentos que não devem ser consumidos pela mulher que amamenta, segundo a opinião de 24 mães de Murumuru, Munić́pio de Marabá, PA. 1980.}

$\begin{array}{ll}\begin{array}{l}\text { Alimentos de } \\ \text { origem }\end{array} & \text { Freqüencia* } \\ \text { animal } & \begin{array}{l}\text { Alimentos de Freqüencia* } \\ \text { origem } \\ \text { vegetal }\end{array}\end{array}$

$\begin{array}{lcll}\text { Caça } & 12 & \text { Manga } & 5 \\ \text { Paca } & 7 & \text { Laranja } & 4 \\ \text { Caititu } & 4 & \text { Abobora } & 3 \\ \text { Veado } & 3 & \text { Pimenta } & 2 \\ \text { Tatu } & 2 & \text { Fava } & 2 \\ \text { Porco } & 2 & \text { Banana } & 2 \\ \text { Pato } & 2 & \text { Feijão } & 2 \\ \text { Capote } & 2 & \text { Pepino } & 1 \\ \text { Anta } & 2 & \text { Castanha do Pará } & 1 \\ \text { Peru } & 2 & \text { Fruta Azeda } & 1 \\ \text { Testiculo Bovino } & 1 & \text { Tangerina } & 1 \\ \text { Jabuti } & 1 & \text { Abacaxi } & 1 \\ \text { Galinha D'Angola } & 1 & \text { Mamão } & 1 \\ \text { Surubim } & 1 & \text { Caju } & 1 \\ \text { Galinha } & 1 & & \end{array}$

- Resposta Múltipla

Caça do mato, sem especificar qual. 
animal que não deve ser ingerido no período de lactação, nas duas comunidades. Em São Félix aparecem ainda, com freqüência elevada, tabus sobre o consumo de peixes de couro (tão abundantes nos rios que banham essa localidade), e sobre o consumo de ovos. Soma-se a isso o baixo consumo de leite constatado em pesquisa anteriormente publicada ${ }^{15}$, o que sugere uma possível carência protếca por ocasião da amamentação.

Quanto aos alimentos de origem vegetal, os tabus relacionam-se com mais freqüência às frutas, nas duas localidades.

Os estudos anteriormente citados, realizados pelo CNA nos Estados da Bahia ${ }^{5}$, Espírito Santo $^{10}$, Rio Grande do Norte ${ }^{11}$ e Goiás ${ }^{17}$ confirmam os achados do presente trabalho, pois os alimentos de origem animal foram os mais citados como "alimentos ruins" para quem está amamentando, com destaque para a carne de porco, de boi, peixe de couro e leite. Entre os alimentos de origem vegetal foram mais citados as frutas, especialmente a manga e o abacaxi, além de aparecerem o feijão, o arroz, abóbora e milho.

Stewien ${ }^{14}$, estudando o aleitamento materno em São Luís (MA), identificou "comida reimosa" como o principal alimento a não ser ingerido no período de aleitamento materno, seguida de ovos e carne de porco. Segundo Vianna e Britto "comida reimosa" é aquela que agrava certas condições mórbidas ou condiciona outras.

$\mathrm{Na}$ pesquisa realizada na Amazônia, a $\mathrm{CNA}^{12}$ registrou uma percentagem de apenas $4,6 \%$ de mulheres que restringem determinados alimentos durante a lactação, especialmente carne de porco, peixes gordos, pirarucu, carne de caça, carne de pato, frutas ácidas, frutas oleaginosas e gorduras. Os achados destes estudos não diferem daqueles do presente trabalho.

Cabe destacar que na fase de lactação o organismo está com suas necessidades fisiológicas aumentadas, principalmente no que se refere a calorias, proteínas, vitaminas e minerais. Os tabus alimentares encontrados no presente estudo são justamente em relação àqueles alimèntos considerados prioritários para que a nutriz tenha um bom desempenho na lactação, que são principalmente os de origem animal (fontes de proteínas, vitamina A, cálcio e ferro) e frutas (fontes de minerais e vitaminas, principalmente a vitamina C).

Eaton-Evans e Dugdale ${ }^{4}$, na Austrália, revelaram que os alimentos mais evitados pelas mães que amamentam foram, entre outros, o repolho, chocolate e comidas muito temperadas. Já na India, Khanum e Umapathy ${ }^{8}$ e Rao ${ }^{13}$ referem como alimentos mais evitados pelas nutrizes as frutas, batata doce, batata, abóbora, vegetais, ovos e leite.

\section{4 - Motivos apontados para a restrição de cer- tos alimentos}

Com relação aos motivos apontados pelas mães das duas localidades estudadas, para justificarem as práticas alimentares referentes à restrição a certos alimentos consumidos simultaneamente ou a restrição a outros alimentos isolados que são descartados em certos períodos fisiológicos (gestação e lactação) foram construídas as Tabelas 7 e 8.

Como causas alegadas pelas mães para não misturarem leite com determinados alimentos, a mais citada foi "faz mal" e "ofende", sem maiores informações; seguem-se "mata" e "envenena". Os demais motivos relatados referem-se, principalmente, a problemas do sistema digestivo; curiosa a referência a "tctano".

Poucos são os trabalhos sobre o assunto que citam os motivos da rejeição a certos alimentos ou misturas de alimentos. Entre estes destacam. se dois, realizados pela CNA em Cristalina $(G O)^{17}$ e São Paulo do Potengí (RN) ${ }^{11}$, que registraram como causa de não se misturar, por exemplo, leite com manga, a "vomitação"; para leite com frutas, "ofende".

Quanto aos principais motivos incriminados com relação à ingestão simultânea de frutas, novamente "faz mal" e "ofende" figuram em primeiro lugar. Destacam-se, ainda, "mata", "congestão", "envenena" e "cólica". Chama atenção em São Félix, um motivo registrado como "demência".

Já em relação à ingestão simultânea de alguns alimentos, as mães estudadas alegaram, como causas principais, novamente "faz mal" e "ofende", "mata", dá "congestão" e "cólica".

Martins e col. ${ }^{9}$ afirmam que "a associação entre determinados tipos de alimentos e a produção de doenças, assim como a crendice de que a combinação de certos tipos de alimentos é danosa para a saúde é muito comum, sendo importante fator a ser considerado na etiologia da desnutrição". Tabus alimentares são difíceis de serem eliminados, pois estão ligados ao emocional, ao abstrato, à história das pessoas; porém, é importante que sejam conhecidos por aqueles que pretendem desencadear qualquer tipo de intervenção nessa área. 
TABELA 7

Distribuição da frequiência dos motivos apontados pelas mães de São Félix para justificar seus tabus ẹm relação à ingestão de alimentos. Município de Marabá, PA. 1980.

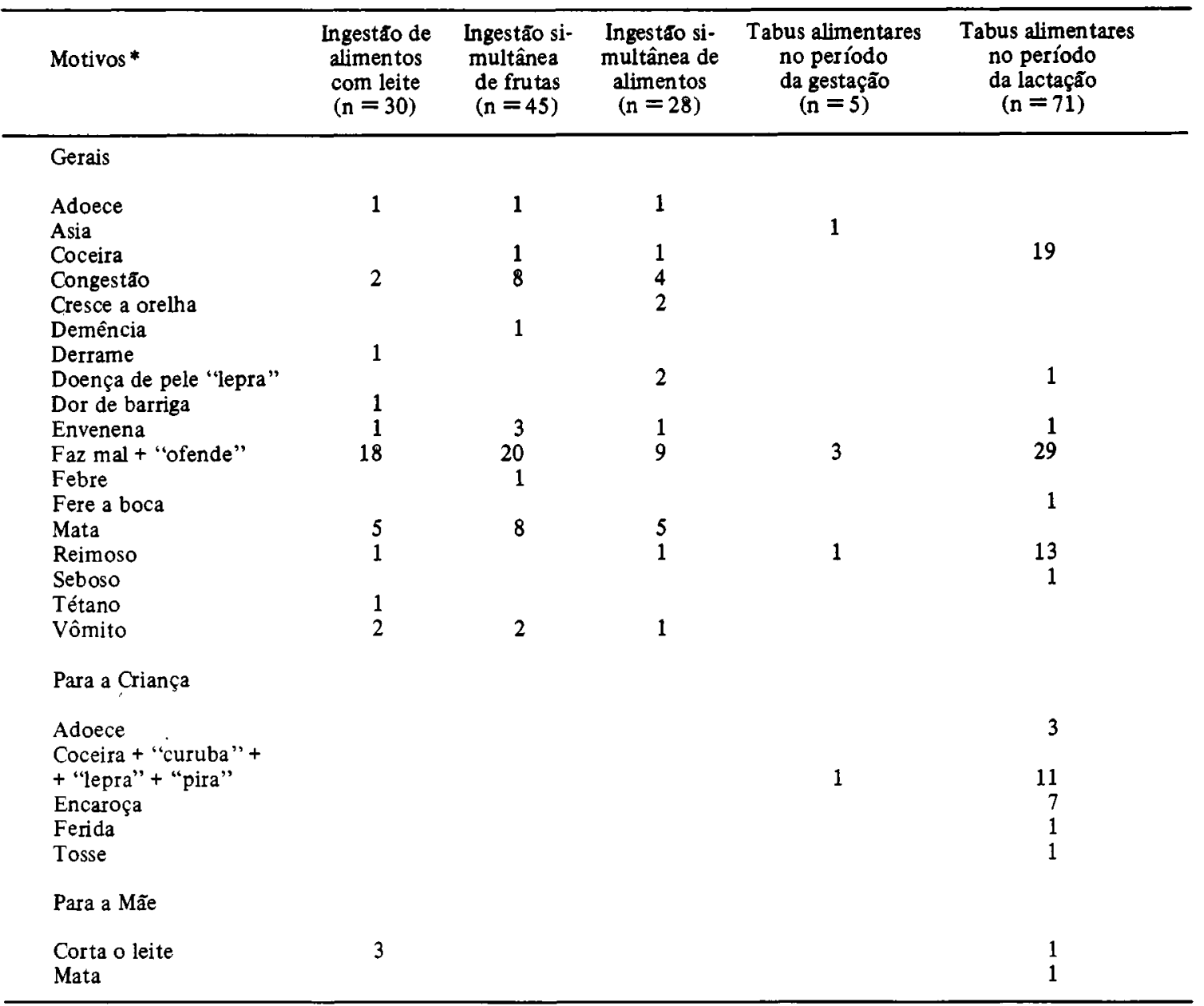

* Resposta múltipla.

Como já referimos, foram poucas as mães que relataram tabus relacionados ao período gestacional. Dentre as causas apontadas, outra vez foi o genériço "faz mal" a única que se sobressaiu. Entretanto, cabe dizer que, embora tenham sido citados uma única vez, alguns motivos chamam atenção por estarem relacionados a este estado fisiológico: causa "aborto", "enjôo", "asia" e "vômito".

Finalmente, quanto às causas motivadoras das restrições alimentares no período da lactação, aparece em primeiro lugar "faz mal" e "ofende", seguido por "coceira", "reimoso", "coceira, curuba e pira na criança" (estes últimos, termos sinônimos). Observa-se que em São Félix os motivos apresentados estão mais relacionados a prejuízos à saúde da criança do que em relação à saúde materna.

Verificou-se em trabalho anterior ${ }^{15}$, efetuado junto a essa população, uma adequação de consumo abaixo de $50 \%$ em relação a nutrientes como cálcio e vitamina $A$, em São Félix, e em cálcio, vitamina A, vitamina B2 e vitamina $C$, em Murumuru. Provavelmente essa situação esteja ligada ao consumo insuficiente de leite, ovos e frutas, que são alvos dos tabus mais freqüentemente apontados pela população, embora também tenha que se lembrar os baixos níveis de renda e de instrução materna nessas localidades. 


\section{TABELA 8}

Distribuição da frequẹencia dos motivos apontados pelas mães de Murumuru para justificar seus tabus em relação à ingestão de alimentos. Município de Marabá, PA. 1980.

\begin{tabular}{|c|c|c|c|c|c|}
\hline Motivos* & $\begin{array}{l}\text { Ingestão de } \\
\text { alimentos } \\
\text { com leite } \\
(n=23)\end{array}$ & $\begin{array}{l}\text { Ingestão si- } \\
\text { multânea } \\
\text { de frutas } \\
(n=11)\end{array}$ & $\begin{array}{l}\text { Ingestão si- } \\
\text { multânea de } \\
\text { alimentos } \\
(n=11)\end{array}$ & $\begin{array}{c}\text { Tabus alimentares } \\
\text { no período } \\
\text { da gestação } \\
(n=6)\end{array}$ & $\begin{array}{l}\text { Tabus alimentares } \\
\text { no período } \\
\text { da lactação } \\
(n=24)\end{array}$ \\
\hline \multicolumn{6}{|l|}{ Gerais } \\
\hline Adoece & 1 & & & & \\
\hline Asia & 2 & & & & \\
\hline Cólica & 1 & 3 & 3 & & \\
\hline Congestão & & 1 & 1 & & \\
\hline Corta o sangue & 2 & & & & 2 \\
\hline Diarréia & 1 & & 1 & & \\
\hline Dor no fígado & & 1 & & & \\
\hline Emagrece & & & & & 1 \\
\hline Envenena & 4 & 1 & 1 & & \\
\hline Faz mal + "ofende" & 13 & 3 & 7 & 1 & 49 \\
\hline Fica preta & 2 & & & & \\
\hline Intoxica & 1 & & 1 & & \\
\hline Mata & 3 & 3 & 4 & & 1 \\
\hline Perigoso & & & & & 1 \\
\hline Reimoso & & & & 1 & 4 \\
\hline Vômito & & 1 & 2 & 1 & \\
\hline \multicolumn{6}{|l|}{ Para a Criança } \\
\hline Adoece & & & & & 1 \\
\hline Coceira & & & & & 3 \\
\hline \multicolumn{6}{|l|}{ Para a Mãe } \\
\hline Aborto & & & & 1 & \\
\hline Ataca a pressão & & & & 1 & \\
\hline Coalha o leite & 1 & & & & \\
\hline Corta o leite & 2 & & & & 1 \\
\hline Enjôo & & & & 1 & \\
\hline Hemorragia & & & & & 1 \\
\hline Prejudica & & & & & 1 \\
\hline
\end{tabular}

\footnotetext{
* Resposta múltipla.
}

TRIGO, M. et al. [Alimentary taboos in the North Region of Brazil]. Rev. Saúde públ., S.Paulo, 23: 455-64, 1989.

ABSTRACT: A study was carried out into alimentary taboos in two localities (São Félix and Murumuru) in the county of Marabá, State of Pará, Brazil. Ninety families were studied in São Félix and thirty-five in Murumuru. As regards the feeding taboos found, the most frequent was that prohibiting the simultaneous ingestion of milk and various types of fruit, including especially mango, orange, cashew and pineapple. The ingestion of eggs with fruit was also considered harmful as well as the eating of mammalian flesh at the same time as fish. Restrictions based on taboos were more frequent during breast feeding than during pregnancy, especially those regarding game flesh and fish that abound in the region under study. The most frequently mentioned reasons for the restrictions were: "the combination causes harm", "the combination kills", "the combination causes congestion" and "it causes vomiting".

KEYWORDS: Food taboo. Diet survey. 


\section{REFERÊNCLAS BIBLIOGRÁFICAS}

1. CASCUDO, L. da C. História da alimentação no Brasil. Belo Horizonte, Ed. Itatiaia, 1983. v.2

2. CASTRO J. de Fisiologia dos tabus. São Paulo, Nestle, 1938.

3. CHAAR, J.M. et al. Contribuição para a melhoria da situaçāo alimentar e nutricional no Brasil - dietas básicas regionais de custo mínimo; relatório da região norte. In: Simpósio Brasileiro de Alimentação e Nutrição, $7^{2}$, Niteroi, 1984. Anais. Niter6i, 1984. p. 55-69.

4. EATON-EVANS, J. \& DUGDAIE, A.E. Food avoidance by breast feeding mother in South East Queensland. Ecol Food Nutr., 19: 123-9, 1986.

5. GOUVEIA E.L. et al. Inquérito sobre hábitos e costumes alimentares; relatório de pesquisa no Município de Bom Jesus da Lapa 1967, Bahia. An. Com nac. Alim, 3(4): 18-20, 1969.

6. JELLIFFE, D.B. Nutricion infantil en paises en desarrollo. México, Ed. Linusa, 1974. p. 81-93.

7. JOYTHY, K.K. et al. A study of the socio-economic diet and nutritional status of a rural community near Hyderabad. Trop. geogr. Med, 15: 403-10, 1963.

8. KHANUM, M.P. \& UMAPATHY, K.P. A survey of the food habits-food and beliefs of pregnant and lactating mothers in Mysore City. Ind. J. Nutr. Diet, 13: 208-17, 1976.

9. MARTINS, AM. Os problemas nutricionais no Brasil. In: Paretta, J.M.M et al. Saúde da comunidade. São Paulo, McGraw Hill do Brasil, 1976. p. 141-56.

10. MINISTÉRIO DA SAÚDE. Comissão Nacional de Alimentação. Inquérito sobre hábitos e recursos alimentares; relatorio sobre estudo alimentar, Município de Colatina, Espírito Santo - Brasil. Rio de Janeiro, 1959.

11. MINISTERRIO DA SAÚDE. Comissão Nacional de Alimentação. Inquérito sobre hábitos e recursos alimentares; relatório sobre estudo alimentar, Município de São Paulo de Potengi, Rio Grande do Norte-Brasil. Rio de Janeiro, 1961.

12. MINISTÉRIO DA SAÚDE. Comissão Nacional de Alimentação. Inquérito sobre consumo de alimentos e nutrientes; avaliação do estado nutritivo e situação económica da população da Amazónia. Bol Com nac. Alim, 4(2): 2-50, 1959.

13. RAO; M. Food beliefs of rural women during the reproductive years in Dharward, India. Ecol Food Nutr., 16: 93-103, 1985.

14. STEWIEN, G.T. de M. O aleitamento materno em São Luis . Maranhão. São Paulo, 1983. [Tese de Doutoramento - Faculdade de Saúde Pública da USP].

15. TRIGO, M. Análise da situaçāo alimentar de dois núcleos populacionais de Marabá, Pará. Alimentação, S.Paulo (80): 17-27, 1985.

16. VIANNA, C.M \& BRITTO, R. da S. Cultura e nutrição na Amazônia, sob hábitos e tabus. Belém, SUDAM, 1982.

17. VELOSO, M.C.C. et al. Relatorio sobre a pesquisa realizada no Município de Cristalina, Goiás, 1966. An Com nac. Alim 2(3): 155-219, 1968.

18. WERNER, D. Onde não há médico: manual para aqueles que vivem e trabalham no campo. $3^{\mathrm{a}} \mathrm{ed}$. São Paulo, Ed. Paulinas, 1980.

19. WITT, A. Alguns conhecimentos sobre nutriçăo ligados à gestação e ao puerpério. Rev. Saúde públ, S.Paulo, 5: 97-102, 1971.

Recebido para publicação em 25/4/1989 Reapresentado en 5/9/1989 Aprovado para publicação em 15/9/1989 